\title{
Genetic Markers Linked to the Dwarfing Trait of Apple Rootstock 'Malling 9'
}

\author{
R.L. Rusholme Pilcher ${ }^{1}$, J-M. Celton, and S.E. Gardiner ${ }^{2}$ \\ The Horticulture and Food Research Institute of New Zealand Ltd, Palmerston North Research \\ Centre, Private Bag 11030, Palmerston North, New Zealand \\ D.S. Tustin \\ The Horticulture and Food Research Institute of New Zealand Ltd, Hawkes Bay Research Centre, \\ Private Bag 1401, Havelock North, New Zealand
}

\begin{abstract}
Additional Index words. Malus $\times$ domestica, trunk cross-sectional area, $D w 1$
Abstract. Little is known of the precise physiological or genetic basis of the phenomenon of rootstock-induced dwarfing in apple (Malus $\times$ domestica Borkh.). Phenotypic assessment and genetic marker analysis of a segregating population of apple rootstocks derived from a cross between the dwarfing rootstock 'Malling 9' ('M.9') and the vigorous rootstock 'Robusta 5' ('R5') was undertaken over a 5-year growth period. Clear segregation of the appearance of the 'Braeburn' scions permitted expert visual classification of each tree into four growth habit classes: dwarfed, semidwarfed, intermediate, or vigorous. Measurements of the cross-sectional area of the trunk of each tree correlated clearly with the expert-assigned phenotypic class. This clear segregation facilitated bulked segregant analysis (BSA) of the 'M.9' $\times$ 'R5' population, and the Dwarfing 1 (Dw1) gene was located in a 2.5-cM region at the top of the linkage group 5 of 'M.9'. The gene $D w 1$ was mapped between the random amplified polymorphic DNA marker NZraAM18_700 and the microsatellite marker CH03a09, identified by BSA and the genome scanning approach, respectively. $D w 1$ is the first reported mapped locus controlling the dwarfing ability of the apple rootstock and maps to a chromosome region not previously known to contain quantitative trait loci or major genes that contribute to tree architecture and development. The identification of a group of trees in the 'M.9' $\times$ ' $R 5$ ' population exhibiting a vigorous phenotype although their rootstocks possess alleles from the $D w 1$ region of ' $M .9$ ' suggests that more loci may be involved in conditioning the dwarfing phenotype. $D w 1$ is a major component of dwarfing, as most of the dwarfing and semidwarfing rootstocks carried the dwarfing allele of this locus. Genetically mapping $D w 1$ is a major step in unraveling the mechanism behind the dwarfing ability of apple rootstocks.
\end{abstract}

Clonal rootstocks have been used in the propagation and cultivation of domestic apple for more than a century. These rootstocks have been selected for a range of desirable characteristics such as pest and disease resistance, cold hardiness, good soil anchorage, and reduced suckering, but perhaps their most significant attribute is their ability to alter the growth and precocity of the grafted scion cultivar. As current horticultural practices intensify, higher density plantings of trees that are capable of fruiting earlier and producing greater yields are required. Dwarfing rootstocks that dramatically reduce the size of the grafted scion and that have also been reported to induce a higher proportion of buds to flower (Atkinson and Else, 2001; Seleznyova et al., 2003) are essential to intensive production methods, enabling a greater yield per unit area and more uniform cropping earlier in the life of the orchard.

Although the phenotypic effects of dwarfing rootstocks are well recognized, the physical or genetic mechanism through which the rootstock exerts size control or precocity is not well understood. Several hypotheses have been proposed to explain the dwarfing effect such as: altered morphology at the graft union restricting the translocation of hormones, assimilates,

Received for publication 24 July 2007. Accepted for publication 5 Oct. 2007. This research was supported in part by the New Zealand Foundation for Research, Science and Technology, contract number C06X0205.

We thank David Chagné for his help during manuscript preparation.

${ }^{1}$ Current address: School of Biological Sciences, University of East Anglia,

Norwich, Norfolk. NR4 7TJ. UK.

${ }^{2}$ Corresponding author. E-mail: sgardiner@hortresearch.co.nz. water or nutrients (Soumelidou et al., 1994a, 1994b), and reduced basipetal translocation of auxins and reduced cytokinin sap levels (Kamboj et al., 1997). Root hydraulic conductivity has also been implicated in the dwarfing phenotype, with conductivity reported to be lower in dwarfing rootstocks than in vigorous rootstocks (Atkinson et al., 2003).

As rootstock-induced effects are cumulative (Costes et al., 2001) and are also affected by scion cultivar and environmental variation, it has been difficult to determine the precise effect that the rootstock has on the growth of the grafted scion. Seleznyova et al. (2003) found that 'Royal Gala' scions grafted onto 'M.9' dwarfing rootstocks possessed a reduced number of nodes per extension growth unit and that the initiation of new metamers (neoformation) in scions grafted onto 'M.9' was halted very soon after budbreak. This reduction in the number of nodes resulted in a smaller number of axillary annual shoots over the following year, and as this growth pattern accumulated, the visually assessed dwarfed phenotype was observed in the scion (Seleznyova et al., 2003).

This reduction in node number is a key difference between the dwarfing effect of some rootstocks and dwarfed or compact scion cultivars, such as the columnar or reduced branching type (Fisher, 1970; Soumelidou et al., 1994a, 1994b). The reduced tree size of these compact cultivars is the result of a shortening of the internode length, rather than a reduction in the number of nodes per shoot. Dwarf mutants that affect internode length have been well characterized in other major crops, particularly cereals, and the genes controlling several dwarf phenotypes have been identified (Dai et al., 2007; Peng et al., 1999). These 
"green revolution" genes encode mutant gibberellin response modulators (Peng et al., 1999) and possess a characteristic 27-amino acid motif, known as the DELLA domain (Hedden, 2003). However, the phenotypic differences between these well-characterized dwarf mutants and the dwarfing apple rootstock suggest that the dwarfing effect of the apple rootstock is likely to be distinct from that of the "green revolution" genes.

Although genes and quantitative trait loci (QTL) that are linked to a range of tree architecture phenotypes related to tree topology and geometry have been identified in apple (Conner et al., 1998; Hemmat et al., 1997; Kenis and Keulemans, 2007; Lawson et al., 1995; Liebhard et al., 2003a; Segura et al., 2007), no genetic marker has been reported for the dwarfing ability of rootstocks. This means that current apple rootstock breeding programs are confined to using conventional breeding strategies. The identification of genetic markers linked to genes influencing the dwarfing ability of 'M.9' would be invaluable to such breeding programs, as their use would avoid the lengthy and costly phenotyping of all individuals in a breeding population and would facilitate the pyramiding of the dwarfing characteristic, along with other key traits such as pest and disease resistance. Closely linked genetic markers would also enable the initiation of high-resolution mapping around the genetic locus and subsequent cloning of the dwarfing gene(s), leading to the elucidation of the mechanism behind the dwarfing ability of apple rootstocks derived from 'M.9'.

Genetic markers for the dwarfing ability of the rootstock Poncirus trifoliata (L.) Raf. 'Flying Dragon' have already been identified (Cheng and Roose, 1995), and it is believed that the inheritance of this $P$. trifoliata rootstock dwarfing phenotype is controlled by a single dominant gene. However, the dwarfing ability of apple rootstocks is thought to be polygenically determined (Tydemann, 1933) and complicated by its environmental context, making it an ideal character for detailed QTL analysis. Although QTL analysis normally involves the detailed characterization of large populations and the generation of saturated genetic maps, bulked segregant analysis (BSA; Michelmore et al., 1991) has recently been successfully used to identify markers linked to major QTLs, influencing traits in other crops such as drought tolerance in maize (Quarrie et al., 1999) and aluminum tolerance in wheat (Ma et al., 2005). The genome scanning approach (GSA) has been used previously in apple to identify microsatellite markers linked to major genes controlling apple scab [Venturia inaequalis (Cooke) G. Winter, 1875] resistance (Erdin et al., 2006; Patocchi et al., 2004, 2005). This method depends upon the existence of a dense genetic map covering the whole genome, from which transferable genetic markers can be selected at regular intervals. The consensus map for apple comprising 840 molecular markers [amplified fragment length polymorphisms (AFLP), random amplified polymorphic DNA (RAPD), sequenced characterized amplified regions (SCAR), and microsatellites] (Liebhard et al., 2003b), which has been recently enlarged with 148 new microsatellite markers (Silfverberg-Dilworth et al., 2006), has enabled the selection of a well-spaced subset of microsatellite markers for genome screening for studies such as ours.

In this study, we used a population derived from a cross between the dwarfing apple rootstock 'M.9' and the vigorous rootstock ' $\mathrm{R} 5$ ' to perform BSA using RAPD primers in association with a GSA using microsatellites to identify genetic markers linked to a major QTL influencing the dwarfing effect of 'M.9'.

\section{Materials and Methods}

Plant material and Phenotypic assessment. A segregating population of 146 seedling rootstocks was generated by crossing 'M.9' with the vigorous rootstock 'R5'. The progeny were grown as stoolbeds [mound layer beds (Hartmann and Kester, 1975)] to produce multiple rooted stool stocks of each rootstock genotype annually. 'Braeburn' scions were budded onto these rootstock stool stocks, and each scion/rootstock combination was replicated between two and three times in the orchard in a randomized incomplete design. The first replicate was planted in the orchard in 2000 as 2-year-old nursery trees. Beginning in 2001, after their first year in the orchard, trees from replicate 1 were annually phenotyped for vigor of scion growth until their fifth orchard year. Replicates 2 and 3 of the 146 rootstocks were propagated in 2000 and were planted as 1 -year-old grafted trees. They were first assessed for vigor at the time of planting out in 2001. Based on the time needed for expression of clear growth differences between rootstocks (from experience with replicate 1, the phenotyping of the trees in replicates 2 and 3 was delayed and performed in the third and fourth year in the orchard. For both groups of trees, measurements were made of trunk circumference $20 \mathrm{~cm}$ above the bud union, and trunk cross-sectional area (TCA) was calculated. In addition, annual expert visual assessments were also made, classifying each tree into one of four growth habit categories: dwarf (similar or smaller than 'M.9'), semidwarf (similar in size to 'M.7' and 'M.26'), intermediate vigor (similar in size to 'MM.106'), or vigorous (similar in size to seedling or 'R5'). All vigor assessments were done by the one expert using the traits of comparative trunk size, crown height and spread, vigor of 1-year-old extension growth, branch density off the trunk, and branch vigor.

BSA. The third and fourth year phenotypic data of the replicate 1 trees were used to select individuals for BSA. DNA from rootstocks that induced phenotypic extremes of scion growth (i.e., dwarf or vigorous) was pooled. Two dwarfing bulks and two vigorous bulks (each consisting of between 10 and 12 individuals, depending upon the number of individuals in each phenotypic class) were constructed. Three dwarfing individuals from the first bulk were repeated in the second dwarfing bulk to compensate for the low number of dwarfing individuals in the segregating population. For the vigorous bulks, individuals were selected that also possessed a high TCA.

Each bulk was screened with 520 RAPD primers and 74 microsatellite markers. RAPD primers that amplified loci in both dwarfing bulks, but not in either vigorous bulk (and vice versa), were screened across a subset of 30 individuals from the 'M.9' × 'R5' population.

Primers amplifying loci exhibiting potential linkages were then screened across the remaining individuals of the population. Microsatellite primers that amplified alleles in one or other set of bulks were screened similarly over the subset of 30 individuals, as well as DNA from 'Fiesta' that was included as a positive control and to aid in allele identification.

For the RAPD analysis, the reaction mixture and amplification program used were as described by Gardiner et al. (1996), except that an annealing temperature of $37{ }^{\circ} \mathrm{C}$ with a reaction volume of $15 \mu \mathrm{L}$ was used. The microsatellite markers used were selected from the consensus apple map of Liebhard et al. (2002) and comprised 74 markers that detected loci at intervals 
of $\approx 20 \mathrm{cM}$ across the apple genome. Primer pairs for each microsatellite were modified as described by Brownstein et al. (1996), where the sequence GTTTCTT was added to the 5' end of each reverse primer to promote adenylation of the $3^{\prime}$ end of the forward strand ("PIG-tailing"), and the sequence TGTAAAACGACGGCCAGT was added to the 5' end of the forward primer to enable the use of an economical method of fluorescent labeling (Schuelke, 2000).

Microsatellite forward and reverse primers were diluted and mixed to give a primer mix for each microsatellite marker with final concentrations of $0.1875 \mu \mathrm{M}$ (forward) and $0.75 \mu \mathrm{M}$ (reverse). A $1.6-\mu \mathrm{L}$ portion of this primer mix was then added to an $8-\mu \mathrm{L}$ polymerase chain reaction $(\mathrm{PCR})$ mix comprising $1 \times$ PCR buffer (without $\mathrm{MgCl}_{2}$; Invitrogen, Carlsbad, CA), $1.5 \mathrm{~mm}$ $\mathrm{MgCl}_{2}, 0.2 \mathrm{~mm}$ of each of dNTP, 0.03 units of Platinum Taq polymerase (Invitrogen), $10 \mathrm{ng}$ of template DNA, and $0.15 \mu \mathrm{M}$ M13 universal primer (VIC-TGTAAAACGACGGCCAGT) labeled at the $5^{\prime}$ end with the fluorescent dye VIC (Applied Biosystems, Foster City, CA). PCR amplification was carried out in a Thermo Hybaid PCR express thermocycler (Thermo Fisher Scientific, Waltham, MA) and the same amplification program was used for all microsatellite reactions: $94{ }^{\circ} \mathrm{C}$ for $5 \mathrm{~min}$ followed by 30 cycles of $94^{\circ} \mathrm{C}$ for $30 \mathrm{~s}, 56^{\circ} \mathrm{C}$ for $45 \mathrm{~s}$, and $72{ }^{\circ} \mathrm{C}$ for $45 \mathrm{~s}$; and then eight cycles of $94{ }^{\circ} \mathrm{C}$ for $30 \mathrm{~s}, 53^{\circ} \mathrm{C}$ for $45 \mathrm{~s}$, and $72{ }^{\circ} \mathrm{C}$ for $45 \mathrm{~s}$; and finally, $72^{\circ} \mathrm{C}$ for $30 \mathrm{~min}$. The PCR products were analyzed on an ABI 3100 Genetic Analyzer using a 22-cm capillary array with POP-6 polymer (Applied Biosystems). Electropherograms were analyzed using ABI Prism GeneScan (version 3.7; Applied Biosystems) and genotype data were visualized graphically and scored using the Genographer program (Benham, 2001).

SCAR MARKER DEVELOPMENT. Two of the loci (NZraAI2_1200 and NZraAE16_1700) detected by the RAPD primers that mapped to the region of interest were converted to SCAR markers and were subsequently mapped in the 'M.9' $\times$ 'R5' population. In each case, the sequence of the PCR product linked to the dwarfing phenotype from 'M.9' was determined. Products of the desired size were excised from agarose gels and DNA was extracted using a gel extraction kit (QIAquick; Qiagen, Hilden, Germany), ligated into pGemTEasy (Promega Corp., Madison, WI), and sequenced as described by Bus et al. (2005). SCAR markers were then designed from the sequence.

An additional SCAR marker, NZscEB108994, derived from a HortResearch (The Horticulture and Food Research Institute of New Zealand Ltd., Palmerston North, New Zealand) apple expressed sequence tag (EST; GenBank accession number EB108994) was also screened (Table 1). PCR amplification for SCAR markers was carried out in a $16-\mu \mathrm{L}$ volume reaction, comprising $1 \mathrm{ng}$ of genomic DNA, $20 \mathrm{~mm}$ Tris- $\mathrm{HCl}$, pH 8.4, $50 \mathrm{~mm} \mathrm{KCl}, 1.3 \mathrm{~mm} \mathrm{MgCl}_{2}, 1 \%$ formamide (Table 1), $0.1 \mathrm{~mm}$ of each dNTP, $0.1 \mu \mathrm{M}$ of each primer, and 0.44 units of Platinum Taq polymerase (Invitrogen) overlaid with $18 \mu \mathrm{L}$ of paraffin oil. DNA fragments were amplified in a Thermo Hybaid PCR express thermocycler (Thermo Fisher Scientific) using the following PCR program; $94{ }^{\circ} \mathrm{C}$ for $2 \mathrm{~min} 45 \mathrm{~s}$ followed by 40 cycles of $94^{\circ} \mathrm{C}$ for $55 \mathrm{~s}, \mathrm{~T}_{\mathrm{a}}$ specific to primer pair (Table 1) for $55 \mathrm{~s}$ and $72^{\circ} \mathrm{C}$ for $1 \mathrm{~min} 39 \mathrm{~s}$, followed by $10 \mathrm{~min}$ at $72{ }^{\circ} \mathrm{C}$. PCR products were separated on a $0.9 \%$ agarose gel comprising $0.45 \%$ agarose (USB Corp., Cleveland, $\mathrm{OH}$ ) and $0.45 \%$ Low Range Ultra Agarose Certified (Bio-Rad, Richmond, CA).

LinKage ANALYSIS AND GENETIC MAPPING. A partial genetic map of 'M.9' around the putative dwarfing locus was constructed using JoinMap version 3.0 (Van Ooijen and Voorrips, 2001). Initial genetic analysis was performed using a logarithm of the odds (LOD) score of 5.0 to associate loci into a linkage group, while the threshold LOD score for mapping was set at the default value of 1.0. The final locus order was determined by extensive proof reading and by minimizing double crossovers flanking single loci. Recombination frequencies were converted to map distance using Kosambi's mapping function (Kosambi, 1944), and chi-square tests were used to identify any segregation distortion of parental alleles. The dwarfing locus was initially positioned using only individuals classified as dwarfing or vigorous.

\section{Results}

Phenotypic assessment of GRAfted scions. Although all three replicates originally comprised 146 trees, losses in the orchard from propagation failures and after planting meant that only 110,120 , and 62 trees from replicates 1, 2, and 3, respectively, were assessed annually for the growth of the 'Braeburn' scion. The final visual assessments of 47 scions common to all replicates were compared using the most recent visual classification data (after 5 years of growth in the orchard for replicate 1 , and 4 years of growth for replicates 2 and 3). Of these 47 genotypes, $36.2 \%$ were assigned to the same phenotypic class across all three replicates and, although this number increased as expected when fewer replicates were compared, vigor ratings for replicates 2 and 3 were as similar to each other as to the earlier planted replicate 1 .

The segregation of the final expert visual phenotypic assessment for all individuals within each replicate is shown in Table 2. The majority of detailed phenotypic and genotypic analysis was carried out using data gathered from replicate 1, as 5 years of growth after grafting was assessed in this replicate. The increase in TCA as a proportion of the previous year's TCA was calculated for each individual and each year. These results were then grouped according to visual classification, and only data from those individuals that belonged to the same

Table 1. Sequenced characterized amplified region markers designed from random amplified polymorphic DNA and expressed sequence tag markers closely linked to the dwarfing locus in 'M.9' apple rootstock.

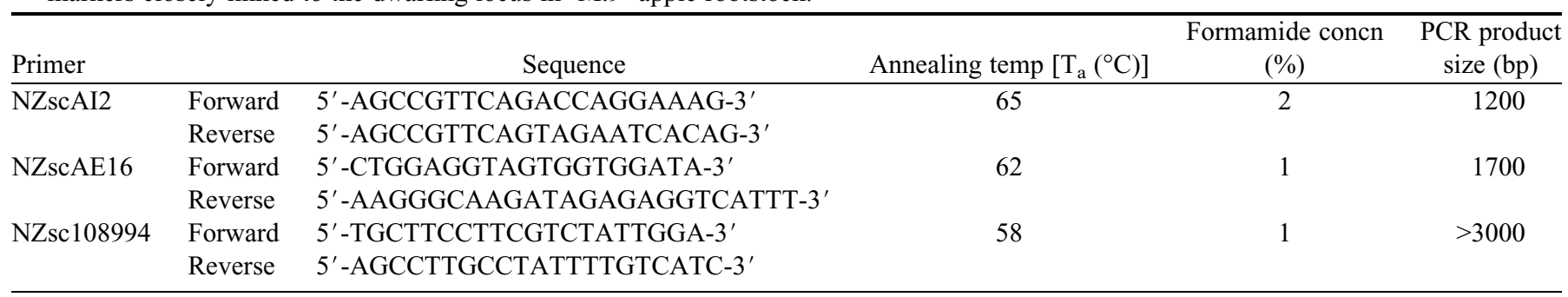


phenotypic class across all years were included and averaged (Fig. 1). As might be predicted, the increase in scion vigor from dwarf to vigorous was correlated with a corresponding increase in the average proportional gain of TCA for each group. Dwarfed, semidwarfed, and intermediate vigor classes followed the same pattern over time, with the largest increase in TCA occurring in the first year of growth assessment; in contrast, trees assessed as vigorous showed the largest increase in TCA in the third year.

Calculation of the gain in TCA over the entire recorded growth period for replicate 1 (5 years; TCA after year 5 as a proportion of TCA after year 1) and comparison with the most recent assigned phenotypic class demonstrated a correlation between the increase in TCA and assigned class (Fig. 2). As might be expected, individuals classified as dwarfed demonstrated smaller increases in TCA and vigorous individuals appeared to contribute the majority of the larger increases in TCA. As previously shown in Fig. 1, the majority of the intermediate individuals were in the lower range of increases in TCA. Interestingly, individuals classed as intermediate in stature, which from Fig. 1 appeared to demonstrate a closer association with TCA size increases common to the vigorous class, can be seen in almost every range of TCA increase in Figure 2, including the outlying highest range.

Table 2. Segregation of the final visual assessment of the growth habit of the 'Braeburn' apple scions on a 'M.9' $\times$ 'Robusta 5' population of rootstocks. In total, 137 genotypes were assessed.

\begin{tabular}{lccc}
\hline Phenotypic class & $\begin{array}{c}\text { Replicate 1 } \\
(\text { no. trees) }\end{array}$ & $\begin{array}{c}\text { Replicate 2 } \\
(\text { no. trees) }\end{array}$ & $\begin{array}{c}\text { Replicate 3 } \\
\text { (no. trees) }^{\mathrm{y}}\end{array}$ \\
\hline Dwarf & 18 & 13 & 12 \\
Semi-dwarf & 11 & 15 & 10 \\
Intermediate & 22 & 23 & 14 \\
Vigorous & 59 & 69 & 26 \\
Trees assessed (no.) & 110 & 120 & 62 \\
\hline
\end{tabular}

${ }^{\mathrm{z} F i n a l}$ visual assessment made after 5 years in orchard.

${ }^{\mathrm{y}}$ Final visual assessment made after 4 years in orchard.

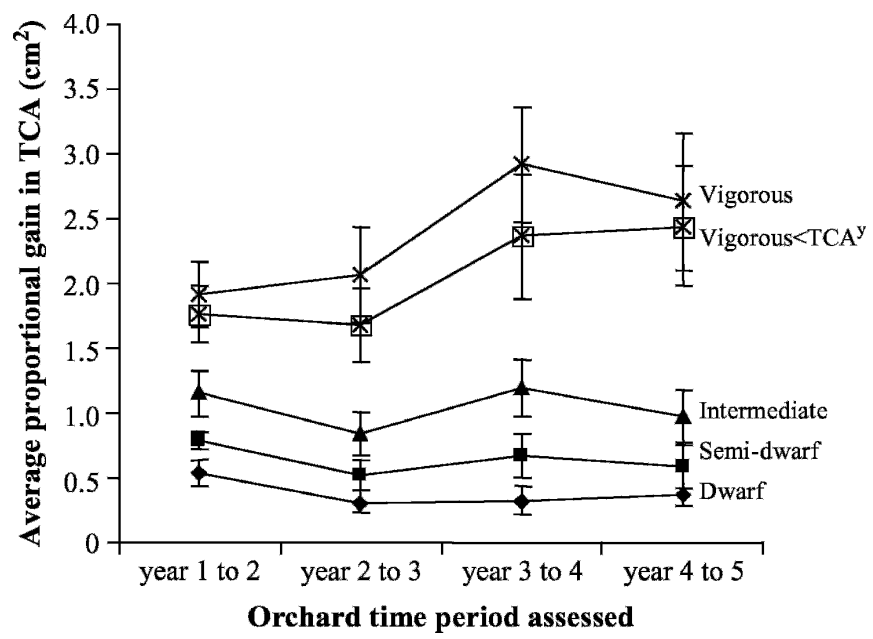

Fig. 1. Average gain in trunk cross-sectional area (TCA) of 'Braeburn' apple scions $^{\mathrm{z}}$ grafted to rootstocks derived from the cross 'M.9' $\times$ 'Robusta 5', and belonging to each phenotypic class in replicate $1 .{ }^{z}$ Only trees that demonstrated same phenotypic class over 5 years assessment. ${ }^{y}$ Individuals assessed as vigorous but demonstrating a lower than expected trunk cross-sectional area and possessing alleles from 'M.9'.

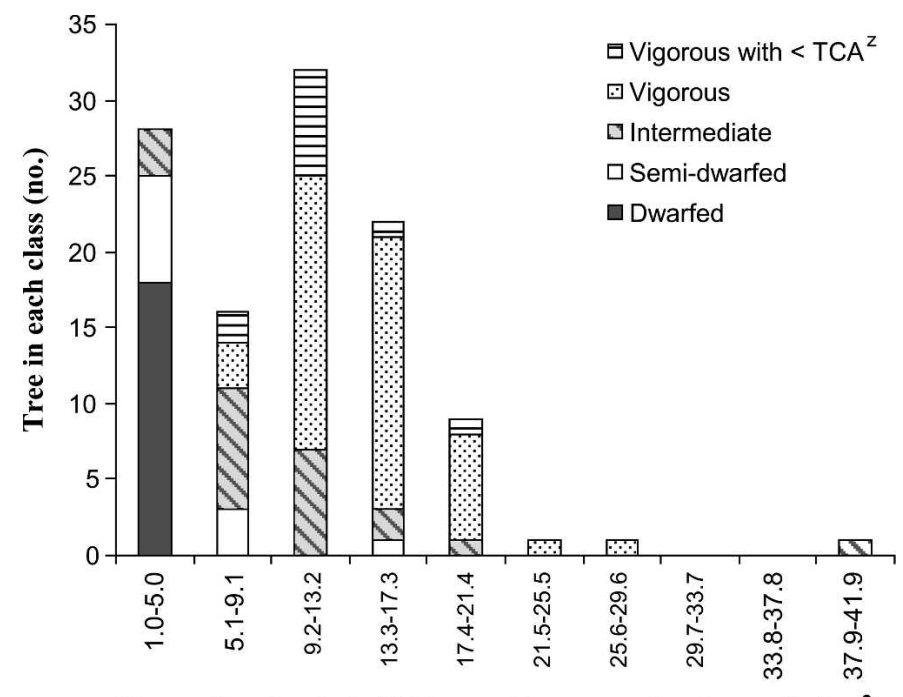

Proportional gain in TCA over 5 years orchard growth $\left(\mathrm{cm}^{2}\right)$

Fig. 2. Comparison of gain in trunk cross-sectional area (TCA) of the 'Braeburn' apple scions on a 'M.9' $\times$ 'Robusta 5' rootstock progeny over 5 years of orchard growth with assigned final phenotypic class. ${ }^{\text {z Individuals }}$ assessed as vigorous but demonstrating a lower than expected trunk crosssectional area, and possessing alleles from 'M.9' around the dwarfing locus.

GENETIC MARKER ANALYSIS OF THE 'M.9' $\times$ 'R5' POPULATION. Of the 595 genetic markers screened over DNA bulks, alleles from 10 RAPD and four microsatellite markers (CH03a09, $\mathrm{CH} 05 \mathrm{e} 06, \mathrm{CH} 04 \mathrm{~g} 09$, and $\mathrm{CH} 05 \mathrm{f06}$ ) appeared to be linked to the expert visual classification of the dwarfing phenotype in replicate 1 . As the majority of these markers originated from the 'M.9' parent, a partial 'M.9' genetic map was constructed after screening these 14 markers across 140 individuals of the 'M.9' $\times$ 'R5' population. Chi-squared analysis of the genotypes at these marker loci identified that the locus detected by the marker NZraAJ13 had an excess of 'M.9' alleles $\left(\chi^{2}=11.1\right.$, $P=0.0008)$. As this marker locus also appeared to result in 24 double crossovers when it was mapped in proximity to the other loci, it was discarded from the mapping exercise. Two of the RAPD markers were converted to SCAR markers (Table 1 and Fig. 3). The segregation of these markers was scored and incorporated in the linkage analysis in place of the original RAPD scores for NZraAI2_1200 and NZraAE16_1700.

All four microsatellite markers that cosegregated with the dwarfing phenotype had been previously shown to be located on linkage group 5 (LG 5) of the apple genetic map (Liebhard et al., 2002). The conservation of marker order and distances between the partial 'M.9' map and the 'Fiesta' $\times$ 'Discovery' reference map strongly indicated that the dwarfing locus was located at the top of LG 5 (Fig. 3).

Initially, the extremes of the population (19 dwarfing and 81 vigorous) were used to position the dwarfing locus, as the genotype of these individuals could be predicted with more confidence as arising from 'M.9' or 'R5', respectively. This first round of mapping located the dwarfing locus at the top of the partial map, above NZraAV11_850. Examination of the individual genotypes of these 100 plants revealed that 12 individuals classified as vigorous, which might be assumed to have 'R5' alleles at the dwarfing locus, exhibited alleles exclusively from the dwarfing parent 'M.9' in a region around this locus. As the genotypes of these 12 individuals placed the putative dwarfing locus outside the identified genomic region of 
'M.9', these genotype-phenotype incongruent (GPI) plants (Gygax et al., 2004) were omitted from the next rounds of mapping. Mapping with the remaining 88 individuals positioned the dwarfing locus in the interval between NZraAM18_700 and CH03a09.

\section{'Fiesta' LG 5}

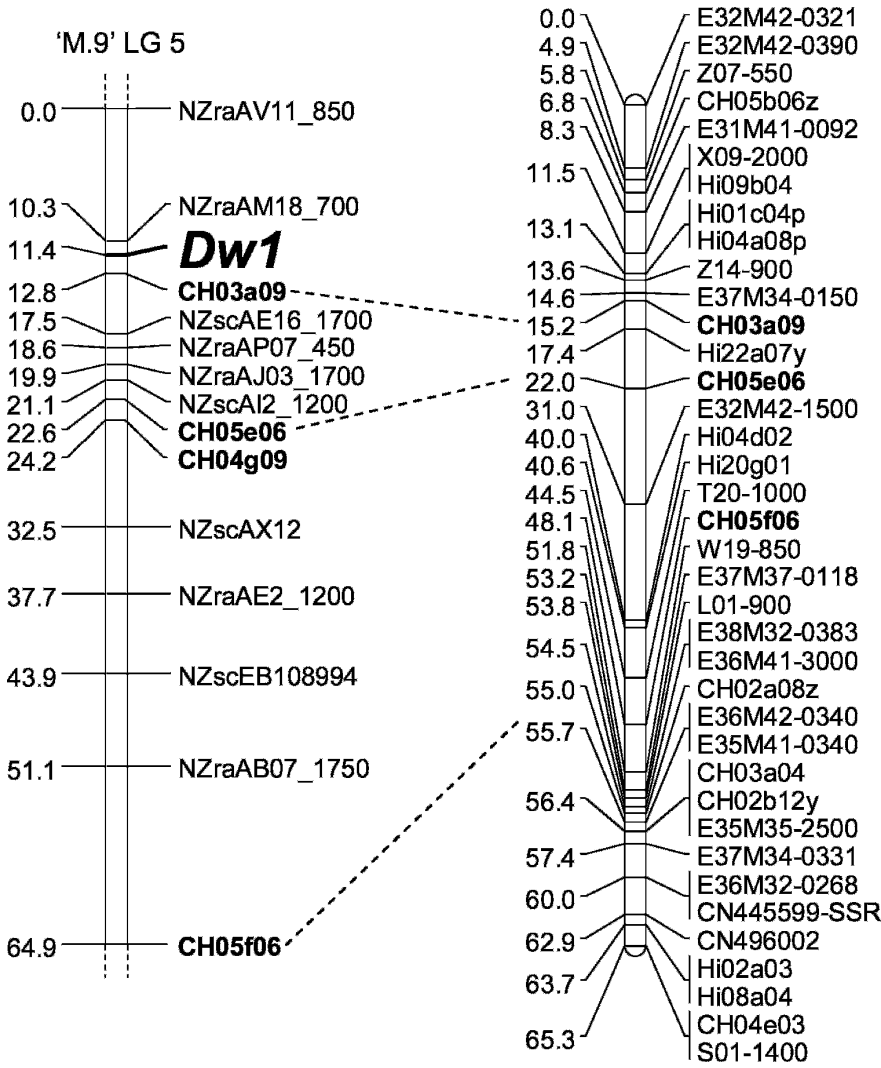

Fig. 3. Partial genetic map of the apple rootstock 'Malling 9' ('M.9') linkage group 5 (LG 5) around the dwarfing locus. LG 5 of 'M.9' aligned with 'Fiesta' LG 5 from Silfverberg-Dilworth et al. (2006). Microsatellite markers mapped in 'M.9' are highlighted in bold text, with dashed lines illustrating microsatellite markers in common with 'Fiesta' LG 5. The dwarfing locus is identified as $D w 1$ in bold text. A gel showing the PCR products from the SCAR marker NZscAE16_1700 of 18 individuals from the 'M.9' $\times$ 'Robusta 5' ('R5') population, phenotyped as dwarfed (DW) or vigorous (V), as well as from mapping population parents 'M.9' and 'R5' is shown, with a 100-bp ladder (Invitrogen, Carlsbad, CA)
The origin of the alleles at these flanking loci was analyzed for all members of each phenotypic class (Table 3). All but one of the individuals classified as dwarfing in their growth habit exhibited alleles from the 'M.9' parent only at the NZraAM18_700 and CH03a09 loci. Semi-dwarfing individuals had mainly alleles from the dwarfing 'M.9' parent, whereas half the individuals classed as intermediate had 'M.9' alleles in the region of the dwarfing locus and the remainder alleles from the vigorous parent ' $\mathrm{R} 5$ '. Examination of the average proportional increase in TCA for the 11 out of 12 of the GPI individuals with alleles from 'M.9' and consistently rated as vigorous indicates that the average TCA increase per year is greater than that observed for dwarfing, semidwarfing, and intermediate individuals $(P=0.002)$, and although the average proportional increase is lower for the GPI individuals than the TCA increase associated with clearly vigorous trees (Fig. 1), this is not significant $(P=0.143)$.

\section{Discussion}

In this study, we localized a dwarfing locus, Dwarfing 1 (Dw1), on the apple genome through a combined approach of BSA and systematic genome scanning of a population of rootstocks segregating for dwarfing ability. $D w l$ is the first locus linked to rootstock-induced dwarfing of the grafted scion to be mapped in apple.

We took advantage of the availability of multiallelic microsatellite markers in apple (Liebhard et al., 2002) and their codominant nature that favors their transferability between different cultivars to identify loci in individuals from the segregating 'M.9' $\times$ 'R5' population, which in turn allowed the identification of the linkage group containing the $D w 1$ locus as LG 5. The conservation of marker order between the 'Fiesta' $\times$ 'Discovery' reference map and the map of 'M.9' (Fig. 3) illustrates the robustness of this approach and the usefulness of a consensus framework map.

It is not possible to compare the position of the rootstock $D w 1$ locus with all the major genes and QTLs that have been mapped for a number of scion architecture traits in some earlier studies because of the lack of markers in common between these populations (Hemmat et al., 1997; Lawson et al., 1995) and the 'M.9' $\times$ 'R5' population. However, in later studies, markers have been mapped in common. A minor QTL controlling height increment that has been mapped to LG 5 of

Table 3. Origin of the alleles at marker loci flanking the dwarfing locus in 'M.9' apple rootstock. In total, 137 genotypes were assessed.

\begin{tabular}{|c|c|c|c|c|c|}
\hline \multirow[b]{2}{*}{ Allele origin } & \multicolumn{5}{|c|}{ Phenotypic class } \\
\hline & $\overline{\text { Dwarf }}$ & Semi-dwarf & Intermediate & Vigorous & Vigorous $<\mathrm{TCA}^{2}$ \\
\hline \multicolumn{6}{|c|}{ Locus NZraAM18_700 } \\
\hline 'M.9' & 19 & 11 & 8 & 1 & 10 \\
\hline 'Robusta 5' & 0 & 4 & 9 & 68 & 1 \\
\hline Not genotyped & 0 & 0 & 5 & 1 & 0 \\
\hline Total individuals & 19 & 15 & 22 & 70 & 11 \\
\hline \multicolumn{6}{|l|}{ Locus CH03a09 } \\
\hline 'M.9' & 17 & 13 & 9 & 0 & 11 \\
\hline 'Robusta 5' & 1 & 2 & 13 & 68 & 0 \\
\hline Not genotyped ${ }^{\mathrm{y}}$ & 1 & 0 & 0 & 2 & 0 \\
\hline Total individuals & 19 & 15 & 22 & 70 & 11 \\
\hline
\end{tabular}

${ }^{2}$ Individuals assessed as vigorous but demonstrating a lower than expected trunk cross-sectional area (TCA) and possessing alleles from 'M.9' in the 64.9-cM region around the dwarfing locus.

'Individuals with missing genotype data. 
the 'Fiesta' $\times$ 'Discovery' population explains 7\% of the phenotypic variability and is one of six QTLs detected in this population for height increment (Liebhard et al., 2003a). This QTL is localized to a position below the interval containing Dwl on the partial 'M.9' map. Kenis and Keulemans (2007) also have identified a region that contains a cluster of tree growth and architecture-related QTLs that contribute to main axis growth and branching traits on the linkage group of apple they designated as LG 15. As this region also contains the previously identified major gene controlling columnar growth habit, Co (Hemmat et al., 1997), it is equivalent to apple LG 10 of the consensus map (Liebhard et al., 2002). Furthermore, it has been shown that LG 10 is homoeologous to LG 5 (Maliepaard et al., 1998). Localization of $D w 1$ on a linkage group homoeologous to the linkage group containing a QTL cluster contributing to main axis growth and branching is worth noting, especially as similar results have been reported by Segura et al. (2007), who mapped QTLs for internode lengthening and form on LG 10 around Co. Although the phenotypes of these scion QTLs, and particularly the Co gene, seem distinct from the rootstock dwarfing characteristic, further dissection and more detailed QTL mapping of the genes involved in rootstock-induced scion dwarfing may reveal similar aspects to these traits and their location on the apple genome as well as their genetic control.

The observation from genotypic data that there was a class of 11 phenotypically vigorous individuals that possessed alleles solely from the dwarfing 'M.9' parent in the region surrounding $D w 1$ indicates that $D w 1$ is not sufficient to explain all the phenotypes present in the 'M.9' $\times$ 'R5' population. The proportional increase in TCA per year seen in replicate 1 for the majority of this group of anomalous individuals lies between that observed for vigorous and intermediate individuals (Fig. 1), and this indicates that these individuals are not the result of a misclassification of intermediate, semidwarfed, or dwarfed trees as vigorous. For this reason, it proved useful to introduce another category (vigorous $<$ TCA) to help rationalize the phenotype of these individuals. This, together with the presence of 'M.9' alleles in the loci flanking Dwl in a high proportion of semidwarfed individuals, could indicate that the four phenotypic classes (dwarfed, semidwarfed, intermediate, and vigorous) could be simplified, or that other genes are required to fully explain the different phenotypes. The segregation of the markers around the $D w 1$ locus was different from the expected 1:1 segregation ratio. Analysis of the $\mathrm{CH} 03 \mathrm{a} 09$ data reveals that 50 rootstock individuals amplified alleles from 'M.9' and 84 amplified alleles from 'R5'. As genotyping was performed only on the rootstocks that were successfully grafted, this ratio may possibly reflect a lower grafting success rate for scions grafted on rootstocks with the $D w 1$ gene, because of their relatively smaller stature compared with scions grafted on rootstocks without $D w 1$.

Although the visual classification of the scions is subjective, it is integrated in the overall tree canopy characteristics and has enabled the mapping of $D w 1$ as a major gene. Comparison of the proportional increase in TCA over the growth period of replicate 1 with phenotypic class (Fig. 1) showed that the lower increases in TCA were associated with dwarfed and semidwarfed individuals compared with vigorous individuals that demonstrated a higher increase in TCA. This indicated that the increase in TCA was directly correlated with the growth pattern of the grafted scion and, furthermore, that selection of those individuals at the extremes of the range with respect to TCA increase and overall growth habit was valid for the mapping of $D w 1$.

Notwithstanding that TCA is conventionally used to characterize tree vigor, and that increase in TCA was used in this study to assess rootstock effect on the scion, Seleznyova et al. (2003) reported that cross-sectional area measured at the base of 3-year-old branches correlated best with the number of extension growth units developed in the third year and thus the cumulative effect of the rootstock over this period of time. Therefore, we suggest that more detailed phenotypic investigation of the individuals in the mapping population could further improve the resolution of the dwarfing trait on a genetic map, particularly as it has been shown that although many basic morphological traits are genetically correlated and exhibit high redundancy (Segura et al., 2007), assessing more than a single trait will minimize misclassification of individuals.

Identifying and positioning $D w l$ on the apple genome is merely the initial step in dissecting the control of this complex and agronomically important phenotype. The 'M.9' $\times$ 'R5' segregating population of 146 rootstocks has proven to be a valuable resource for initiating the elucidation of the genetic control of the dwarfing effect of the 'M.9' rootstock, and work has recently commenced on the further phenotypic assessment of an extended 'M.9' $\times$ 'R5' population. Plans have also been made to genotype and phenotype a succeeding generation from this cross. Coupled with the generation of a complete genetic map, this will enable the identification and location of additional loci that contribute to the dwarfing phenotype (J-M. Celton, unpublished data). In addition, the association of significantly increased precocity of 'M.9' grafted scions (Seleznyova et al., 2007) with dwarfing will be explored. The requirement for markers to assist breeding for dwarfing rootstocks is underscored by the analysis of the individuals classified phenotypically as intermediate in Figure 2, which shows that they are found in nearly every range of TCA increase, including the extremes. The markers linked to $D w 1$ reported here, together with markers identified in ' $\mathrm{R} 5$ ' for resistance to fire blight [Erwinia amylovora (Burrill) Winslow et al.] (Peil et al., 2007) and woolly apple aphid (Eriosoma lanigerum Hausm.; Bus et al., 2007), will be useful for markerassisted selection in rootstock breeding. The markers will also be useful for initiating fine structure mapping and subsequent cloning of $D w 1$. As such, the placement of this locus on a genetic map forms a crucial step in eventually determining the mechanism behind the dwarfing ability of apple rootstocks and comparing this with the mechanism of dwarfing controlled by other known plant-dwarfing mutations.

\section{Literature Cited}

Atkinson, C. and M. Else. 2001. Understanding how rootstocks dwarf fruit trees. Compact Fruit Tree 34:46-49.

Atkinson, C.J., M.A. Else, L. Taylor, and C.J. Dover. 2003. Root and stem hydraulic conductivity as determinants of growth potential in grafted trees of apple (Malus pumila Mill.). J. Expt. Bot. 54:12211229.

Benham, J. 2001. Genographer. 10 Sept. 2007. <http://hordeum.msu. montana.edu/genographer/>.

Brownstein, M.J., J.D. Carpten, and J.R. Smith. 1996. Modulation of non-templated nucleotide addition by Taq DNA polymerase: Primer modifications that facilitate genotyping. Biotechniques 20:10041010 . 
Bus, V.G.M., D. Chagné, H.C.M. Bassett, D. Bowatte, F. Calenge, J.M. Celton, C.-E. Durel, M.T. Malone, A. Patocchi, A.C. Ranatunga, E.H.A. Rikkerink, D.S. Tustin, J. Zhou, and S.E. Gardiner. 2007. Genome mapping of three major resistance genes to woolly aphid (Eriosoma lanigerum Hausm.). Tree Genet. Genomes. Online DOI 10.1007/s11295-007-0103-3.

Bus, V.G.M., E.H.A. Rikkerink, W.E. van de Weg, R.L. Rusholme, S.E. Gardiner, H.C.M. Bassett, L.P. Kodde, L. Parisi, F.N.D. Laurens, E.J. Meulenbroek, and K.M. Plummer. 2005. The Vh2 and $V h 4$ scab resistance genes in two differential hosts derived from Russian apple R12740-7A map to the same linkage group of apple. Mol. Breed. 15:103-116.

Cheng, F.S.H. and M.L. Roose. 1995. Origin and inheritance of dwarfing by the citrus rootstock Poncirus trifoliata 'Flying-Dragon'. J. Amer. Soc. Hort. Sci. 120:286-291.

Conner, P.J., S.K. Brown, and N.F. Weeden. 1998. Molecular-marker analysis of quantitative traits for growth and development in juvenile apple trees. Theor. Appl. Genet. 96:1027-1035.

Costes, E., J.C. Salles, and G. Garcia. 2001. Growth and branching pattern along the main axis of two apple cultivars grafted on two different rootstocks. Acta Hort. 557:131-138.

Dai, M., Y. Zhao, Q. Ma, Y. Hu, P. Hedden, Q. Zhang, and D.X. Zhou. 2007. The rice YAB1 gene is involved in the feedback regulation of gibberellin metabolism. Plant Physiol. 144:121-133.

Erdin, N., S. Tartarini, G.A.L. Broggini, F. Gennari, S. Sansavini, C. Gessler, and A. Patocchi. 2006. Mapping of the apple scab-resistance gene $V b$. Genome 49:1228-1245.

Fisher, D.V. 1970. Spur strains of 'McIntosh' discovered in British Columbia, Canada. Fruit Var. Hort. Dig. 24:27-32.

Gardiner, S.E., H.C.M. Bassett, D.A.M. Noiton, V.G. Bus, M.E. Hofstee, A.G. White, R.D. Ball, R.L.S. Forester, and E.H.A. Rikkerink. 1996. A detailed linkage map around an apple scab resistance gene demonstrates that two disease resistance classes both carry the $V f$ gene. Theor. Appl. Genet. 93:458-493.

Gygax, M., L. Gianfranceschi, R. Liebhard, M. Kellerhals, C. Gessler, and A. Patocchi. 2004. Molecular markers linked to the apple scab resistance gene $V b j$ derived from Malus baccata jackii. Theor. Appl. Genet. 109:1702-1709.

Hartmann, H.T. and D.E. Kester. 1975. Plant propagation principles and practices. 3rd ed. Prentice Hall, Englewood Cliffs, NJ.

Hedden, P. 2003. The genes of the green revolution. Trends Genet. 19:5-9.

Hemmat, M., N.F. Weeden, P.J. Conner, and S.K. Brown. 1997. A DNA marker for columnar growth habit in apple contains a simple sequence repeat. J. Amer. Soc. Hort. Sci. 122:347-349.

Kamboj, J.S., P.S. Blake, J.D. Quinlan, A.D. Webster, and D.A. Baker. 1997. Recent advances in studies on the dwarfing mechanism of apple rootstocks. Acta Hort. 451:75-82.

Kenis, K. and J. Keulemans. 2007. Study of tree architecture of apple (Malus $\times$ domestica Borkh.) by QTL analysis of growth traits. Mol. Breed. 19:193-208.

Kosambi, D.D. 1944. The estimation of map distances from recombination values. Ann. Eugen. 12:172-175.

Lawson, D.M., M. Hemmat, and N.F. Weeden. 1995. The use of molecular markers to analyze the inheritance of morphological and developmental traits in apple. J. Amer. Soc. Hort. Sci. 120:535-537. Liebhard, R., L. Gianfranceschi, B. Koller, C.D. Ryder, R. Tarchini, W.E. Van de Weg, and C. Gessler. 2002. Development and characterisation of 140 new microsatellites in apple (Malus $\times$ domestica Borkh.). Mol. Breed. 10:217-241.

Liebhard, R., M. Kellerhals, W. Pfammatter, M. Jertmini, and C. Gessler. 2003a. Mapping quantitative physiological traits in apple (Malus $\times$ domestica Borkh.). Plant Mol. Biol. 52:511-526.

Liebhard, R., B. Koller, L. Gianfranceschi, and C. Gessler. 2003b. Creating a saturated reference map for the apple (Malus $\times$ domestica Borkh.) genome. Theor. Appl. Genet. 106:1497-1508.
Ma, H.X., G.H. Bai, B.F. Carver, and L.L. Zhou. 2005. Molecular mapping of a quantitative trait locus for aluminium tolerance in wheat cultivar Atlas 66. Theor. Appl. Genet. 112:51-57.

Maliepaard, C., F.H. Alston, G. van Arkel, L.M. Brown, E. Chevreau, F. Dunemann, K.M. Evans, S. Gardiner, P. Guilford, A.W. van Heusden, J. Janse, F. Laurens, J.R. Lynn, A.G. Manganaris, A.P.M. den Nijs, N. Periam, E. Rikkerink, P. Roche, C. Ryder, S. Sansavini, H. Schmidt, S. Tartarini, J.J. Verhaegh, M. Vrielink-van Ginkel, and G.J. King. 1998. Aligning male and female linkage maps of apple (Malus pumila Mill.) using multi-allelic markers. Theor. Appl. Genet. 97:60-73.

Michelmore, R.W., I. Paran, and R.V. Kesseli. 1991. Identification of markers linked to disease-resistance genes by bulked segregant analysis: A rapid method to detect markers in specific genomic regions by using segregating populations. Proc. Natl. Acad. Sci. USA 88:9828-9832.

Patocchi, A., B. Bigler, B. Koller, M. Kellerhals, and C. Gessler. 2004. Vr2: A new apple scab resistance gene. Theor. Appl. Genet. 109:1087-1092.

Patocchi, A., M. Walser, S. Tartarini, G.A.L. Broggini, F. Gennari, S. Sansavini, and C. Gessler. 2005. Identification by genome scanning approach (GSA) of a microsatellite tightly associated with the apple scab resistance gene $V m$. Genome 48:630-636.

Peil, A., T. Garcia-Liberos, K. Richter, F.C. Trognitz, B. Trognitz, M.V. Hanke, and H. Flachowsky. 2007. Strong evidence for a fire blight resistance gene of Malus robusta located on linkage group 3. Plant Breed. 126:470-475.

Peng, J., D.E. Richards, N.M. Hartley, G.P. Murphy, K.M. Devos, J.E. Flintham, J. Beales, L.J. Fish, A.J. Worland, F. Pelica, D. Sudhakar, P. Christou, J.W. Snape, M.D. Gale, and N.P. Harberd. 1999. 'Green revolution' genes encode mutant gibberellin response modulators. Nature 400:256-261.

Quarrie, S.A., V. Lazić-Jančić, D. Kovačević, A. Steed, and S. Pekić. 1999. Bulk segregant analysis with molecular markers and its use for improving drought resistance in maize. J. Expt. Bot. 337:1299-1306.

Schuelke, M. 2000. An economic method for the fluorescent labeling of PCR fragments. Nat. Biotechnol. 18:233-234.

Segura, V., C. Denancé, C.-E. Durel, and E. Costes. 2007. Wide range QTL analysis for complex architectural traits in a 1-year-old apple progeny. Genome 50:159-171.

Seleznyova, A.N., T.G. Thorp, M. White, S. Tustin, and E. Costes. 2003. Application of architectural analysis and AMAPmod methodology to study dwarfing phenomenon: The branch structure of 'Royal Gala' apple grafted on dwarfing and non-dwarfing rootstock/interstock combinations. Ann. Bot. (Lond.) 91:665-672.

Seleznyova, A.N., D.S. Tustin, M.D. White, and E. Costes. 2007. Analysis of the earliest observed expression of dwarfing rootstock effects on young apple trees using Markovian models. Acta Hort. 732:79-84.

Silfverberg-Dilworth, E., C.L. Matasci, W.E. Van de Weg, M.P.W. Van Kaauwen, M. Walser, L.P. Kodde, V. Soglio, L. Gianfranceschi, C.E. Durel, S. Tartarini, T. Yamamoto, B. Koller, C. Gessler, and A. Patocchi. 2006. Microsatellite markers spanning the apple (Malus $\times$ domestica Borkh.) genome. Tree Genet. Genomes 2:202-224.

Soumelidou, K., N.H. Battey, P. John, and J.R. Barnett. 1994a. The anatomy of the developing bud union and its relationship to dwarfing in apple. Ann. Bot. (Lond.) 74:605-611.

Soumelidou, K., D.A. Morris, N.H. Battey, J.R. Barnett, and P. John. 1994b. Auxin transport capacity in relation to the dwarfing effect of apple rootstocks. J. Hort. Sci. 69:719-725.

Tydemann, H.M. 1933. Breeding experiment with 'Paradise' apple rootstocks. J. Pomol. Hort. Sci. 11:214-236.

Van Ooijen, J.W. and R.E. Voorrips. 2001. JoinMap version 3.0, Software for the calculation of genetic linkage maps. Plant Research International, Wageningen, The Netherlands. 